\title{
Spontaneous Trabeculectomy Bleb Reformation and Regain of Function Following Phacoemulsification
}

\author{
Wassef Chanbour $^{1}$, Hani Chanbour ${ }^{2}$, Karim F. Tomey ${ }^{1}$, Ziad Khoueir ${ }^{1}$ \\ 1. Ophthalmology, Beirut Eye \& ENT Specialist Hospital, Beirut, LBN 2. Medicine, Lebanese University Faculty of \\ Medicine, Beirut, LBN
}

Corresponding author: Ziad Khoueir, ziad@khoueir.com

\begin{abstract}
Phacoemulsification and cataract surgery in general often lead to trabeculectomy bleb failure. We herein describe an unusual occurrence in a 79-year-old female who had a failed trabeculectomy bleb for one year prior to presentation, and whose failed bleb became reformed, and she regained function on the first day post-phacoemulsification, manifesting as a decrease in intraocular pressure. Topical corticosteroids were used for one month postoperatively and the bleb remained functional over more than six months of followup. It is most likely that the intraocular pressure elevation that occurs during phacoemulsification was responsible for the reformation of the bleb, even after having been a failed bleb for a whole year.
\end{abstract}

Categories: Ophthalmology

Keywords: phacoemulsification, trabeculectomy, bleb reformation, glaucoma, cataract

\section{Introduction}

Trabeculectomy remains the most commonly performed glaucoma surgery to control intraocular pressure (IOP) [1]. Cataracts are known to progress faster following this surgery [2-3], and hence many glaucomatous eyes with blebs will require cataract surgery at some stage.

Multiple studies have shown that performing cataract surgery in an eye with a functioning filtering bleb can result in bleb failure and IOP elevation [4-5] while other studies reported that phacoemulsification had no effect on the bleb function or the IOP [6-7].

Review began $07 / 23 / 2021$ Review ended 07/26/2021 Published 08/07/2021

\section{○ Copyright 2021}

Chanbour et al. This is an open access article distributed under the terms of the Creative Commons Attribution License CC-BY 4.0., which permits unrestricted use, distribution, and reproduction in any medium, provided the original author and source are credited.
The ocular inflammatory reaction post phacoemulsification has been proposed to be the cause of bleb failure through promoting conjunctival scarring, and this is true especially during the first year following trabeculectomy. In contrast, performing phacoemulsification at a later time has been found to be less likely to have an adverse effect on the bleb, and it was not a risk factor for further increase in IOP [8].

We herein describe a case of spontaneous old filtration bleb reopening following cataract surgery.

\section{Case Presentation}

A 79-year-old female, who had previously undergone a trabeculectomy 15 years earlier in her right eye for primary open-angle glaucoma, presented with progressive decline in her visual acuity over one year, from $20 / 25$ to $20 / 50$. She was found to have a $2+$ nuclear cataract and an absent bleb, although it had been present one year earlier.

Intraocular pressure in that eye on a timolol/dorzoalmide $(6.8 \mathrm{mg} / 22.3 \mathrm{mg}$ per $\mathrm{mL})$ combination, brimonidine $(0.02 \%)$, and travoprost $(0.004 \%)$ was $10 \mathrm{mmHg}$.

Under peri-bulbar anesthesia, and through a 3.0-mm clear-corneal incision at 11 o'clock, non-complicated phacoemulsification with in-the-bag foldable intraocular lens implantation was performed on the right eye. A tobramycin $0.3 \%$ and dexamethasone $0.1 \%$ combination was started postoperatively four times per day, to be tapered during the following month.

On the first postoperative day, the patient presented with a pressure of $6 \mathrm{mmHg}$ and an elevated and formed bleb, which was encapsulated (Figures 1-2). On gonioscopy, the internal trabeculectomy ostium was found to be patent (Figure 3). All the topical anti-glaucoma drops were stopped. 


\section{Cureus}

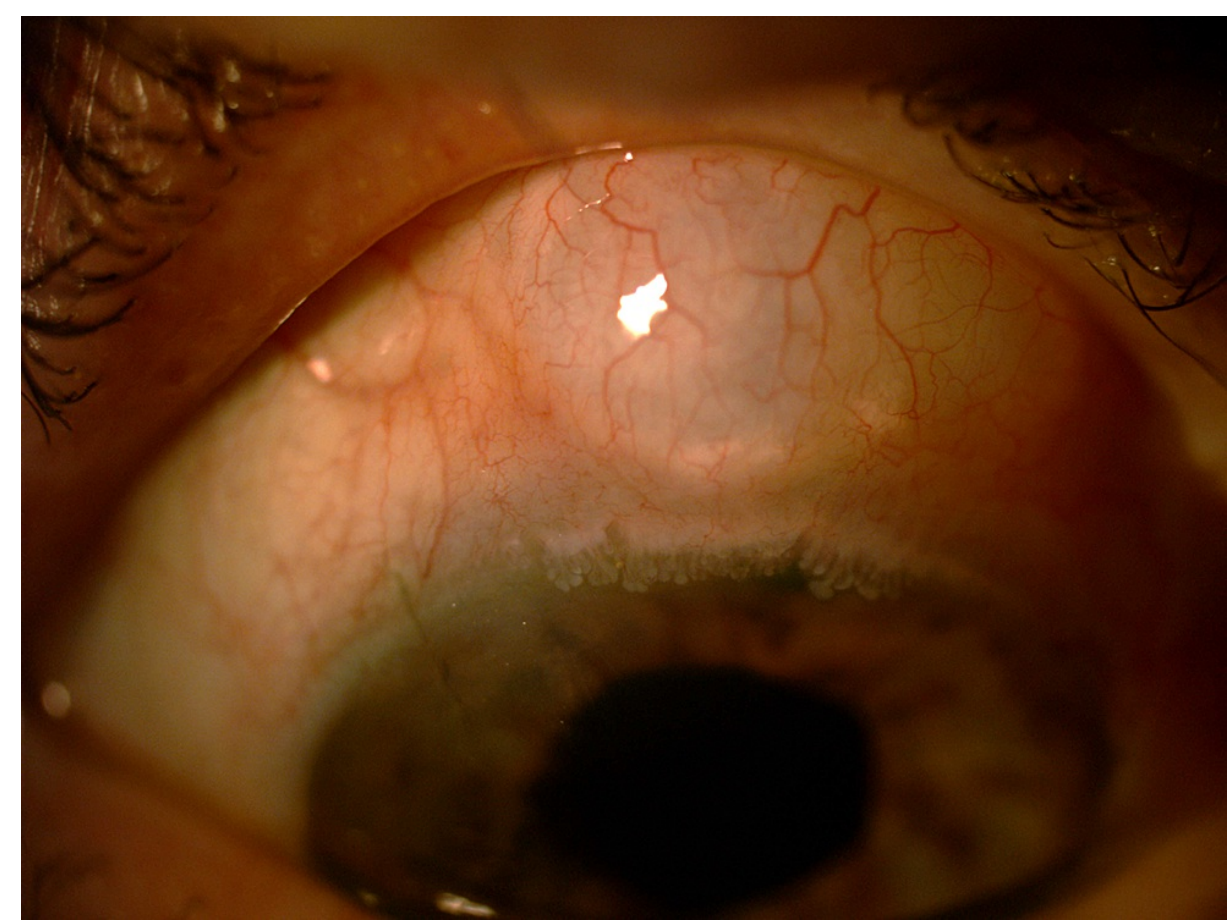

FIGURE 1: Day 1 post-phacoemulsification photo showing the encapsulated bleb

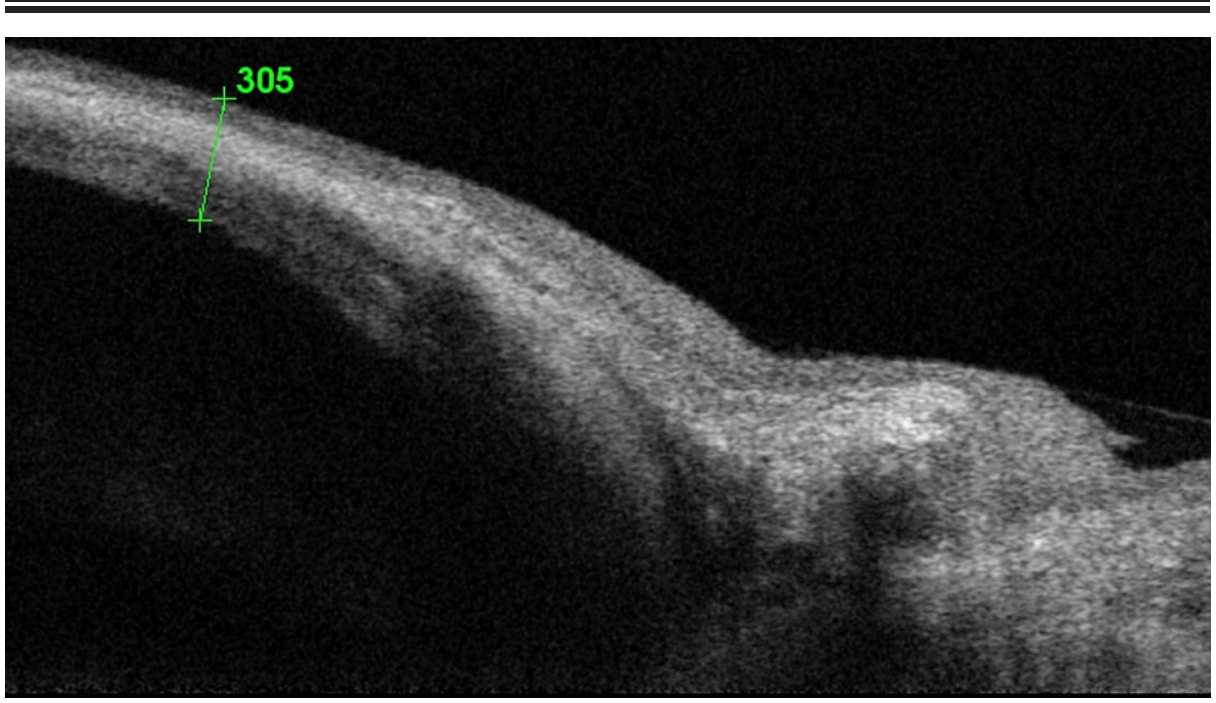

FIGURE 2: OCT showing the elevated bleb with subconjunctival fluid with a conjunctival thickness of $\mathbf{3 0 5} \boldsymbol{\mu m}$

ОСТ: optical coherence tomography 


\section{Cureus}

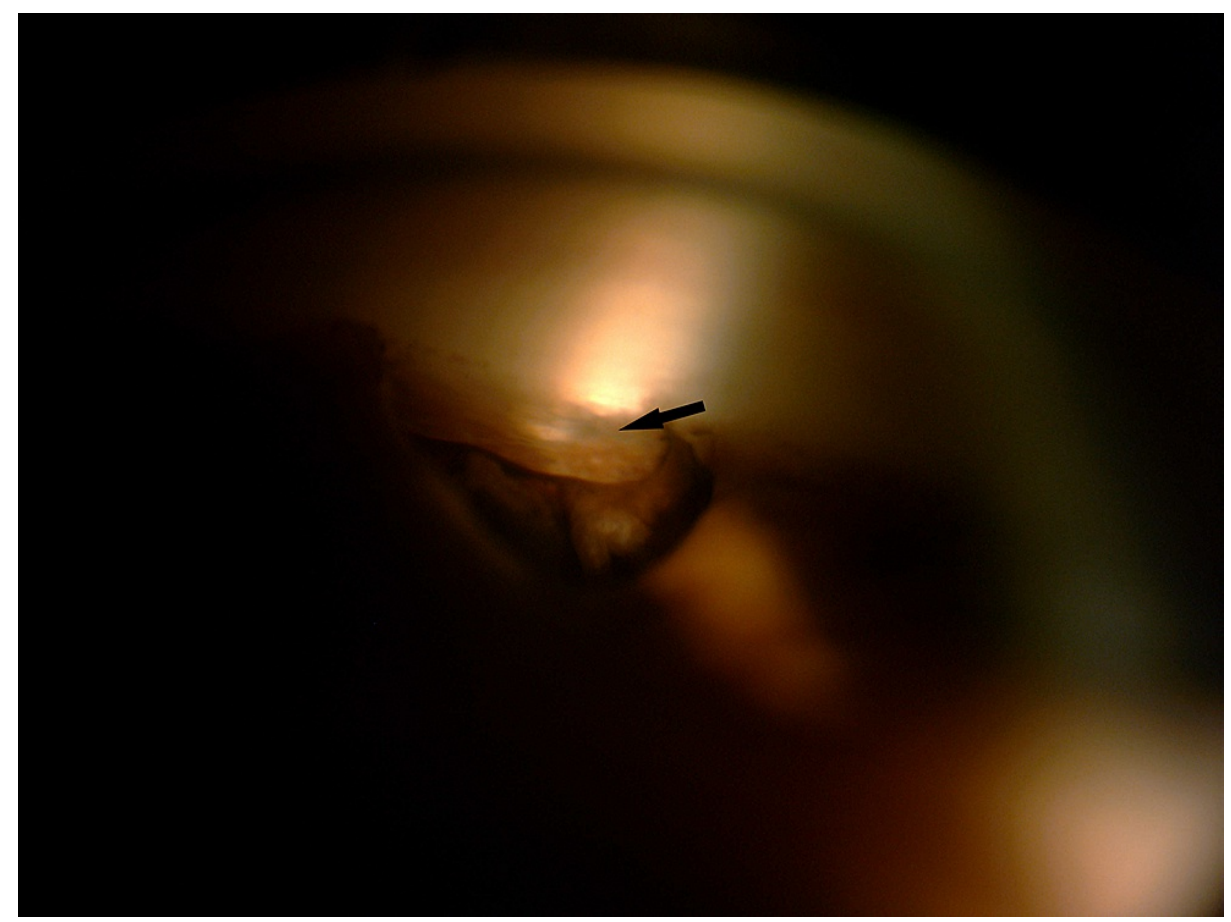

\section{FIGURE 3: Gonioscopy showing the surgical iridectomy and the patent internal ostium of the trabeculectomy (arrow)}

The follow-up was uneventful. Six months later, the IOP stabilized at $10 \mathrm{mmHg}$ on travoprost only. The bleb was still present and the final uncorrected visual acuity was 20/20 in the operated eye.

\section{Discussion}

To our knowledge, this is the first case to be reported of a failed trabeculectomy filtration bleb spontaneously reforming and regaining its function following phacoemulsification.

The most probable explanation is that the event occurred during the surgery. Khng et al. proved that IOP could reach $60 \mathrm{mmHg}$ during coaxial and bimanual phacoemulsification [9]. We theorize that the high intraoperative intraocular pressure reopened the trabeculectomy flap (sort of an ab interno revision), leading to a decrease in the postoperative IOP to the extent of slight hypotony.

Iatrogenic bleb formation following cataract surgery has been reported previously. It occurs if the wound leaks under a sealed conjunctiva post-cataract surgery, even in eyes that had not previously undergone trabeculectomy [10-11]. In our case, the corneal incision was located away from the trabeculectomy flap and the bleb location. Also, the corneal incision was sutured with 10-0 nylon. That is why the possibility of an inadvertent filtering bleb caused by the incision was eliminated.

The newly formed bleb was encapsulated but functional, and thus the significant decrease in IOP obviated the use of some glaucoma medications. We believe also that the continuous use of potent topical corticosteroids following the cataract surgery decreased the postoperative inflammation, thus preventing the new bleb from scarring. The use of topical corticosteroids in the early postoperative period after trabeculectomy has been found to be efficient in stabilizing the IOP and visual function in patients with progressive glaucomatous disease [12]. In a study conducted by Klink J et al., 13.3\% of the trabeculectomy patients had a decreased IOP of more than $2 \mathrm{mmHg}$ post phacoemulsification, but it was not associated with an improved bleb morphology [13].

In brief, this case illustrates that bleb reformation and regain of function can occur, though rarely, following phacoemulsification and even after the trabeculectomy had failed for a long time, one year in our case. Topical steroids should be used in the early postoperative period in order to maintain bleb function.

\section{Conclusions}

Our case demonstrates that not all cataract surgeries have ill effects on eyes previously operated on for glaucoma. The bleb can be reformed and the trabeculectomy flap reopened even one year after having been scarred, and this is conceivably caused by the bouts of severe IOP elevation that usually occur during the 


\section{Additional Information \\ Disclosures}

Human subjects: Consent was obtained or waived by all participants in this study. Conflicts of interest: In compliance with the ICMJE uniform disclosure form, all authors declare the following: Payment/services info: All authors have declared that no financial support was received from any organization for the submitted work. Financial relationships: All authors have declared that they have no financial relationships at present or within the previous three years with any organizations that might have an interest in the submitted work. Other relationships: All authors have declared that there are no other relationships or activities that could appear to have influenced the submitted work.

\section{References}

1. Vinod K, Gedde SJ, Feuer WJ, Panarelli JF, Chang TC, Chen PP, Parrish RK 2nd: Practice preferences for glaucoma surgery: a survey of the American Glaucoma Society. J Glaucoma. 2017, 26:687-93. 10.1097/IJG.0000000000000720

2. Rajavi Z, Moezzi-Ghadim H, Kamrava K: The effect of trabeculectomy on cataract formation or progression . J Ophthalmic Vis Res. 2009, 4:84-9.

3. The AGIS Investigators: The Advanced Glaucoma Intervention Study, 8: risk of cataract formation after trabeculectomy. Arch Ophthalmol. 2001, 119:1771-9. 10.1001/archopht.119.12.1771

4. Wang X, Zhang H, Li S, Wang N: The effects of phacoemulsification on intraocular pressure and ultrasound biomicroscopic image of filtering bleb in eyes with cataract and functioning filtering blebs. Eye (Lond). 2009, 23:112-6. 10.1038/sj.eye.6702981

5. Swamynathan K, Capistrano AP, Cantor LB, WuDunn D: Effect of temporal corneal phacoemulsification on intraocular pressure in eyes with prior trabeculectomy with an antimetabolite. Ophthalmology. 2004, 111:674-8. 10.1016/j.ophtha.2003.08.025

6. Crichton AC, Kirker AW: Intraocular pressure and medication control after clear corneal phacoemulsification and AcrySof posterior chamber intraocular lens implantation in patients with filtering blebs. J Glaucoma. 2001, 10:38-46. 10.1097/00061198-200102000-00008

7. Casson RJ, Riddell CE, Rahman R, Byles D, Salmon JF: Long-term effect of cataract surgery on intraocular pressure after trabeculectomy. Extracapsular extraction versus phacoemulsification. J Cataract Refract Surg. 2002, 28:2159-64. 10.1016/s0886-3350(02)01501-8

8. Awai-Kasaoka N, Inoue T, Takihara Y, Kawaguchi A, Inatani M, Ogata-Iwao M, Tanihara H: Impact of phacoemulsification on failure of trabeculectomy with mitomycin-C. J Cataract Refract Surg. 2012, 38:41924. 10.1016/j.jcrs.2011.09.035

9. Khng C, Packer M, Fine IH, Hoffman RS, Moreira FB: Intraocular pressure during phacoemulsification. J Cataract Refract Surg. 2006, 32:301-8. 10.1016/j.jcrs.2005.08.062

10. Jain SS: Inadvertent filtering bleb following sutureless cataract surgery . Indian J Ophthalmol. 2005, 53:1968. 10.4103/0301-4738.16681

11. Geyer O: Management of large, leaking, and inadvertent filtering blebs with the neodymium. YAG laser . Ophthalmology. 1998, 105:983-7.10.1016/S0161-6420(98)96023-7

12. Starita RJ, Fellman RL, Spaeth GL, Poryzees EM, Greenidge KC, Traverso CE: Short- and long-term effects of postoperative corticosteroids on trabeculectomy. Ophthalmology. 1985, 92:938-46. 10.1016/s01616420(85)33931-3

13. Klink J, Schmitz B, Lieb WE, et al.: Filtering bleb function after clear cornea phacoemulsification: a prospective study. Br J Ophthalmol. 2005, 89:597-601. 10.1136/bjo.2004.041988 